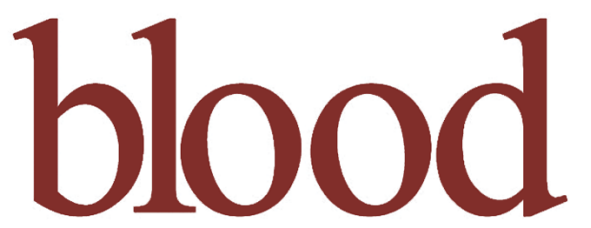

2002 99: 4509-4516

doi:10.1182/blood.V99.12.4509

\title{
The lymphoproliferative defect in CTLA-4-deficient mice is ameliorated by an inhibitory NK cell receptor
}

Cynthia A. Chambers, Joonsoo Kang, Yongjian Wu, Werner Held, David H. Raulet and James P. Allison

Updated information and services can be found at:

http://bloodjournal.hematologylibrary.org/cgi/content/full/99/12/4509

Articles on similar topics may be found in the following Blood collections:

Immunobiology (3426 articles)

Information about reproducing this article in parts or in its entirety may be found online at:

http://bloodjournal.hematologylibrary.org/misc/rights.dt|\#repub_requests

Information about ordering reprints may be found online at:

http://bloodjournal.hematologylibrary.org/misc/rights.dtl\#reprints

Information about subscriptions and ASH membership may be found online at:

http://bloodjournal.hematologylibrary.org/subscriptions/index.dtl

Blood (print ISSN 0006-4971, online ISSN 1528-0020), is published semimonthly by the American Society of Hematology, 1900 M St, NW, Suite 200, Washington DC 20036.

Copyright 2007 by The American Society of Hematology; all rights reserved.

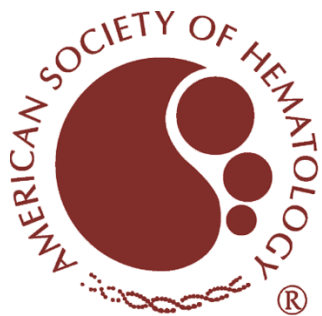




\section{The lymphoproliferative defect in CTLA-4-deficient mice is ameliorated by an inhibitory NK cell receptor}

Cynthia A. Chambers, Joonsoo Kang, Yongjian Wu, Werner Held, David H. Raulet, and James P. Allison

T-cell responses are regulated by activating and inhibiting signals. CD28 and its homologue, cytotoxic T-lymphocyte antigen 4 (CTLA-4), are the primary regulatory molecules that enhance or inhibit T-cell activation, respectively. Recently it has been shown that inhibitory natural killer (NK) cell receptors (NKRs) are expressed on subsets of $\mathrm{T}$ cells. It has been proposed that these receptors may also play an important role in regulating T-cell responses. However, the extent to which the NKRs modulate peripheral T-cell homeostasis and activation in vivo remains unclear. In this report we show that NK cell inhibitory receptor Ly49A engagement on $\mathrm{T}$ cells dramatically limits $\mathrm{T}$-cell activation and the resultant lymphoproliferative disorder that occurs in CTLA-4deficient mice. Prevention of activation and expansion of the potentially autoreactive $\mathrm{CTLA}^{-1-}{ }^{-/} \mathrm{T}$ cells by the Ly49A- mediated inhibitory signal demonstrates that NKR expression can play an important regulatory role in T-cell homeostasis in vivo. These results demonstrate the importance of inhibitory signals in T-cell homeostasis and suggest the common biochemical basis of inhibitory signaling pathways in T lymphocytes. (Blood. 2002; 99:4509-4516)

๑) 2002 by The American Society of Hematology

\section{Introduction}

Cytotoxic T-lymphocyte antigen 4 (CTLA-4), a homologue of the T-cell costimulatory molecule CD28, is proposed to regulate the initiation and termination of T-cell responses. Accumulating in vitro and in vivo evidence suggests that CTLA-4 engagement inhibits T-cell activation (reviewed in Chambers et $\mathrm{al}^{1}$ ). CTLA-4 engagement inhibits the up-regulation of early activation T-cell surface antigens, prevents cell cycle transit, and inhibits secretion of interleukin 2 (IL-2), whereas CTLA-4 blockade enhances T-cell responses. ${ }^{2}$ The strongest evidence for the inhibitory role of CTLA-4 has been demonstrated in CTLA-4-deficient mice. CTLA$4^{-1-}$ mice develop a fatal lymphoproliferative disorder characterized by a massive expansion of lymphocytes dependent initially on polyclonal, CD28-dependent activation of $\mathrm{CD} 4{ }^{+} \mathrm{T}$ cells, subsequent lymphocytic infiltration into nonlymphoid tissues, and death by 3 to 4 weeks of age. ${ }^{3-6}$ Polyclonal CD4 ${ }^{+}$CTLA-4-deficient T-cell activation is observed in the absence of immunization and exogenous antigen, as demonstrated in mice expressing a single self-peptide/major histocompatibility complex (MHC) class II complex (C.A.C., manuscript in preparation). We propose that CTLA-4 provides dominant inhibitory signals to prevent autoreactive peripheral T-cell activation and maintain T-cell homeostasis. ${ }^{5}$ Accordingly, this model predicts that the lymphoproliferation observed in CTLA-4 ${ }^{-1-}$ mice may be prevented by an alternate inhibitory signal.

Natural killer (NK) cells are a subset of effector lymphocytes that can directly lyse transformed target cells without prior priming. The activation of NK cells is in part controlled by inhibitory molecules that recognize MHC class I molecules. The murine inhibitory NK receptors (NKRs) fall into 2 groups: a family of lectinlike Ly49 molecules and CD94/NKG2 heterodimers. Each of the Ly49 molecules demonstrates a unique and specific MHC class I recognition pattern. For example, the Ly49A molecule binds relatively strongly to $\mathrm{H}-2 \mathrm{D}^{\mathrm{d}}$ and weakly to $\mathrm{D}^{\mathrm{k}, \mathrm{s}, \mathrm{b}}$ haplotypes on target cells. ${ }^{7,8}$ Inhibitory Ly49 molecules were initially characterized as NK-specific receptors that provide dominant inhibitory signals and prevent NK cell lysis of targets in the presence of the specific self-MHC molecules. NK lysis would then occur on decreased or loss of expression of MHC class I molecules on the surface of target cells, an alteration often observed during transformation and some viral infections.

Recently, it has been shown that the inhibitory NKRs are more widely expressed than initially suspected. Varying proportions of NKT, $\gamma \delta \mathrm{T}$ cells and human and murine $\alpha \beta \mathrm{CD}^{+} \mathrm{T}$ cells with memory phenotype express the inhibitory NKR. ${ }^{9-13}$ Based on this expression pattern, it has been proposed that these receptors might also regulate T-lymphocyte activation or T-cell responses. Results with T-cell clones demonstrate that human inhibitory and activating NKR, namely KIRs and KARs, respectively, can influence T-cell cytotoxicity in vitro. ${ }^{14-18}$ In vitro mixed lymphocyte reactions by murine $\mathrm{CD}^{+} \mathrm{T}$ cells are also inhibited by the engagement of Ly49A. ${ }^{19}$ Recently, it has been shown that lymphocytic choriomeningitis virus (LCMV)-specific cytotoxic T-lymphocyte (CTL) responses and antitumor responses are decreased following immunization when $\mathrm{CD} 8{ }^{+} \mathrm{T}$ cells express Ly49A transgene, ${ }^{20,21}$ showing
From the Department of Pathology, University of Massachusetts Medical School, Worcester; Department of Neurobiology, Stanford University, Palo Alto, CA; Ludwig Institute for Cancer Research, Lausanne, Switzerland; Division of Immunology, Department of Molecular and Cellular Biology, Cancer Research Laboratory, Howard Hughes Research Institute, University of California, Berkeley.

Submitted November 7, 2001; accepted February 11, 2002.

Supported by Human Frontiers Science Program (C.A.C.) and National Institutes of Health (D.H.R. and J.P.A.). C.A.C. and J.K. are recipients of the Worcester Foundation for Biomedical Research Scholar Award and C.A.C. is a
Cancer Research Institute Investigator. J.P.A. is a member of the Howard Hughes Research Institute.

Reprints: Cynthia A. Chambers, Department of Pathology, University of Massachusetts Medical School, 55 Lake Ave N, Worcester, MA 01655; e-mail: cynthia.chambers@umassmed.edu.

The publication costs of this article were defrayed in part by page charge payment. Therefore, and solely to indicate this fact, this article is hereby marked "advertisement" in accordance with 18 U.S.C. section 1734.

(C) 2002 by The American Society of Hematology 
that NKRs on $\mathrm{T}$ cells can modulate antigen-specific responses. However, the physiologic importance of NKR-mediated inhibition in regulating mature peripheral T-cell homeostasis and tolerance in vivo is unknown. Moreover, the biochemical pathways used by these inhibitory signals and how they interact/intersect with T-cell receptor (TCR)-mediated signaling pathways are unclear.

In this study we examined the potential of inhibitory NKRs to regulate systemic autoreactive $\mathrm{T}$-cell activation and tested the ability of an alternative inhibitory signal to compensate for the loss of CTLA-4-mediated signals in T-cell homeostasis. We show that introduction of the Ly49A transgene $(\mathrm{Tg})^{19}$ into CTLA-4-deficient mice ${ }^{22}$ expressing $\mathrm{H}-2 \mathrm{D}^{\mathrm{d}}$ regulates the lymphoproliferative disease associated with the loss of CTLA-4 function: Ly49A expression on T cells inhibits the activation and the accumulation of the CTLA- ${ }^{-1-} \mathrm{T}$ cells only in the presence of Ly49A ligand $\mathrm{H}-2 \mathrm{D}^{\mathrm{d}}$. The prevention of rampant proliferation of CTLA- $4^{-1-}$ T cells by the Ly49A-mediated inhibitory signals is accompanied by a selective decrease in the level of tyrosine phosphorylation of proteins involved in the signaling pathways for T-cell activation. Collectively, these results demonstrate that engagement of Ly49A receptors on $\mathrm{T}$ cells can compensate for the loss of CTLA-4 function and prevent activation of the autoreactive T cells in vivo. These results demonstrate the role of inhibitory receptors, including inhibitory NKRs in maintaining peripheral T-cell homeostasis and tolerance.

\section{Materials and methods}

\section{Mice}

Mice heterozygous for the CTLA-4 null mutation ${ }^{22}$ were backcrossed 3 times to C57BL/6 before being crossed to mice expressing the Ly49A transgene (MHC class I promoter, IgM enhancer) and H-2D ${ }^{\mathrm{d}}$ (B10.D2). ${ }^{19}$ The Ly49ATg $^{+}$mice used in this study are healthy and display no pathogenesis, ${ }^{19}$ in contrast to other strains of mice that develop autoimmunity due to altered thymocyte selection. ${ }^{24}$ Mice heterozygous for the Ly49A transgene, $\mathrm{H}-2 \mathrm{D}^{\mathrm{d}}$, and the CTLA-4 mutation were intercrossed to obtain Ly49A transgenic, H-2D ${ }^{d}$, CTLA- $4^{+/+}$, CTLA- $4^{+/-}$, and CTLA- $4^{-1-}$ animals. Similar results have been obtained with animals that are more extensively backcrossed to the B6 background ( $>6$ times). Animals were typed for the genotype of the ctla- 4 gene by polymerase chain reaction and for the presence of the transgene and MHC class I by flow cytometric analysis of peripheral blood lymphocytes. Animals were maintained in microisolators in accordance with the Animal Care and Use Regulations of the University of California, Berkeley, and University of Massachusetts Medical School.

\section{Media and reagents}

RPMI (Biowhittaker, Walkersville, MD) was supplemented with $10 \%$ calf serum (Hyclone, Logan, VT), 2 mM 2-mercaptnoethanol (Sigma, St Louis, MO), $2 \mathrm{mM}$ L-glutamine, and 100U/mL antibiotics (Gibco, Gaithersburg, MD). Recombinant human IL-2 was obtained from Cetus. Aminoethyl carbazole (AEC) substrate was obtained from Sigma. Streptavidinhorseradish peroxidase (HRP) was obtained from Jackson Immunoresearch Lab (West Grove, PA). The following monoclonal antibodies (mAbs) were used: anti-CD4-phycoerythrin (PE)/tricolor (TC), anti-CD44-PE, H57biotin (anti-TCR $\alpha \beta$ ), anti-CD69-fluoroescein isothiocyanate (FITC)/biotin, anti-CD25-FITC, anti-thy1.2-PE/FITC, anti-CD62L-PE, anti-CD45RBFITC, anti-Sca-1-FITC (all from Pharmingen, San Diego, CA); anti-B220FITC, anti-CD $8 \alpha-\mathrm{TC}$, streptavidin-TC, -PE (Caltag, Burlingame, CA); anti-CD4-613 and CD8-613 (Gibco). Anti-Ly49A antibody YE5 was prepared as described in Held et al. ${ }^{19}$ Anti-bromodeoxyuridine (anti-BrdU) antibody was purchased from Becton Dickinson. Annexin V staining kit was purchased from Pharmingen. In some annexin V staining experiments, propidium iodide was used to exclude dead cells from analysis. Flow cytometric analysis was performed as described. ${ }^{22}$

\section{Histologic analysis}

Tissue samples from the pancreas, liver, lung, heart, skin, and kidney were routinely removed. The samples were fixed in $10 \%$ buffered formalin and embedded in paraffin. Sections were fixed on slides and stained with hematoxylin and eosin by conventional techniques.

\section{Cell preparation and flow cytometric analysis}

For all of the mice analyzed the caudal, mesenteric, brachial, submaxillary, inguinal, and popliteal lymph nodes were collected and pooled. Single-cell suspensions were prepared from the pooled nodes and the spleen and, following red blood cell lysis, the cells were counted and used for analysis. Flow cytometric analysis was performed as described. Briefly, cells $\left(0.5-1 \times 10^{6}\right.$ cells/sample) were preincubated with $24 \mathrm{G} 2$ to block Fc $\gamma \mathrm{R}$ and were then incubated with the indicated antibodies. For annexin V staining the samples were prepared as above, but were also incubated with the annexin V staining kit as per the instructions (Pharmingen). The samples were analyzed on a 4-color flow cytometer (XL; Coulter, Hialeah, FL) and 50000 events were collected per sample. The listmode files were analyzed using WINMIDI software. The statistical significance of the absolute cell numbers in the groups of animals analyzed were compared using the Student $t$ test.

\section{BrdU incorporation analysis}

Animals were injected every 9 to 12 hours $(100 \mu \mathrm{g} /$ mouse $)$ for 2 days and analyzed 12 hours or 3 days after the last injection, as described..$^{5,22}$ Briefly, samples from the lymph node and spleen were stained for cell surface markers and fixed with $70 \%$ ethanol, followed by paraformaldehyde treatment. The fixed cells were digested with DNase I and incubated with anti-BrdU-FITC antibody, as described. ${ }^{22}$ The cells were washed extensively and immediately analyzed by fluorescence-activated cell sorting, as described above. Routinely, 50000 or 100000 events were collected.

\section{Western blotting and immunoprecipitation}

Lymph node $\mathrm{T}$ cells were purified ex vivo by negative enrichment using anti-B220 beads (Dynal, Oslo, Norway) to ensure that the purification procedure was performed rapidly and at $4^{\circ} \mathrm{C}$. The purity of the cell preparation was confirmed by flow cytometry. Lysates from purified lymph node $\mathrm{T}$ cells were prepared as described, ${ }^{23}$ at a concentration of $1 \times 10^{7}$ cells/100 $\mu \mathrm{L}$ NP-40 lysate buffer. Protein concentrations were determined using the Protein Assay Kit (Biorad, Hercules, CA). To further ensure that equal amounts of protein were loaded on the gel or used for the immunoprecipitation, varying volumes of the sample lysates were run on a gel and analyzed by standard Western blotting. The proteins were resolved on $8 \%, 10 \%$, or $12 \%$ polyacrylamide gels. Western blot analysis was performed as described..$^{23}$ Tyrosine phosphorylated proteins were detected using 4G10-biotin and developed with SA-HRPO (Upstate Biotechnology, Lake Placid, NY). The blots were stripped and reprobed with antibodies to the indicated proteins, namely, ERK2, cbl, ZAP-70, SHP-1, SHP-2, PLC $\gamma 1$, vav (all from Santa Cruz Biotechnology, Santa Cruz, CA). Equal amounts of protein of the indicated samples were immunoprecipitated as described. ${ }^{24}$ Anti-CD3 $\zeta$ antibody 387 was a gift of L. Samelson.

\section{Results}

\section{Ly49A ligation inhibits T-cell activation and expansion in CTLA-4-deficient T cells}

The Ly49ATg ${ }^{+}$mice used in this experiment are healthy, contain normal numbers of $\mathrm{T}$ cells, and have no overt alterations in thymocyte development. ${ }^{19}$ Ly49A is expressed at high levels on all $\mathrm{T}$ cells in these animals. To test if the alternate inhibitory signal mediated by Ly49A could compensate for the loss of the putative inhibitory signal via CTLA-4, the Ly49A transgene was introduced 


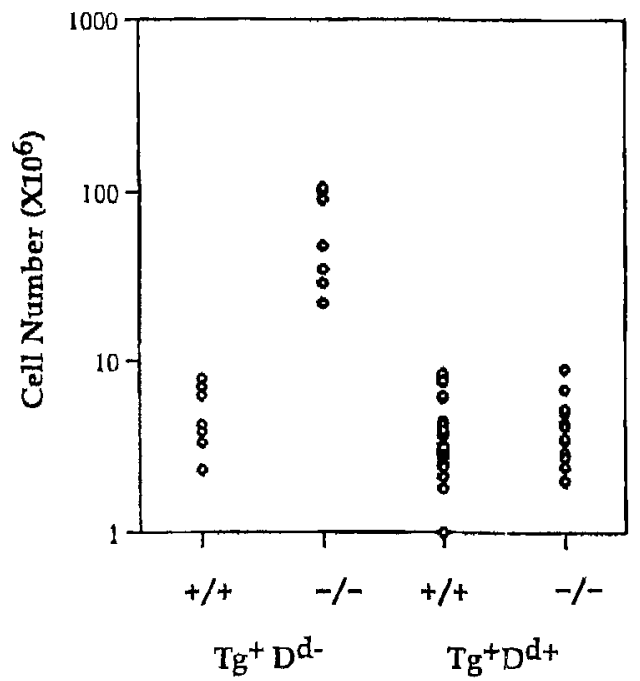

Figure 1. Expression of Ly49A transgene in the presence of MHC class I H-2Dd prevents lymphocyte expansion in CTLA-4-deficient mice. Single-cell suspensions of lymph node cells were prepared, counted, and analyzed for the expression of cell surface markers using antibodies specific for CD4, CD8, and TCR $\alpha \beta$. Absolute number of $\mathrm{CD}^{+}{ }^{+}$in Ly49ATg ${ }^{+} \mathrm{H}-2^{\mathrm{b}} / \mathrm{H}-2^{\mathrm{d}}$, CTLA-4 wild-type and deficient animals. Each dot represents a single animal. Ly49ATg ${ }^{+} \mathrm{H}-2 \mathrm{D}^{\mathrm{b}}$ : CTLA-4 $4^{+/+,+-}, \mathrm{n}=9$; $\mathrm{CTLA}_{-4}^{-1-}, \mathrm{n}=9$; Ly49ATg $^{+} \mathrm{H}-2 \mathrm{D}^{\mathrm{d}} \mathrm{CTLA}^{-4^{+/+,+/-}}, \mathrm{n}=31 ; \mathrm{CTLA}^{-4^{-/-}}, \mathrm{n}=18$. These animals were analyzed at 3 to 5 weeks of age, because the CTLA-4 ${ }^{-1-}$ mice that develop the lymphoproliferative disease die by 4 weeks of age. The difference in the absolute $\mathrm{CD} 4^{+}$T-cell number in the CTLA-4 ${ }^{-1-}$ mice expressing Ly $49 \mathrm{~A}$ transgene in the presence versus absence of the ligand $\mathrm{H}-2 \mathrm{D}^{\mathrm{d}}$ was statistically significant $(P<.001)$, whereas there was no statistically significant difference in the number of $\mathrm{CD}^{+}{ }^{+} \mathrm{T}$ cells between the Ly49ATg ${ }^{+} \mathrm{H}-2 \mathrm{D}^{\mathrm{d}+} \mathrm{CTLA}^{-} 4^{-/-}$and the littermate control mice. into the CTLA-4-deficient mice. Expression of the Ly49A transgene on $\mathrm{T}$ cells in $\mathrm{H}-2 \mathrm{D}^{\mathrm{d}}$ CTLA-4-deficient mice results in a 10 -fold reduction in the absolute number of lymph node $\mathrm{CD} 4^{+} \mathrm{T}$ cells compared to Ly49ATg ${ }^{+} \mathrm{H}-2^{\mathrm{b}}\left(\mathrm{D}^{\mathrm{b}}\right) \mathrm{CTLA}-4^{-1-}(P<.001)$ or nontransgenic CTLA- $4^{-1-}$ mice $(P<.001)$ and leads to a restoration of a T-cell pool comparable in size (no statistically significant difference) to that of normal mice (Figure 1). There is a 2- to 3 -fold or a 5- to 6-fold decrease in the proportion of $\mathrm{CD} 4^{+} \mathrm{T}$ cells in Ly49ATg $^{+}$H-2 ${ }^{\text {d }}$ CTLA- $4^{-1-}$ mice compared to wild-type or Ly49ATg $^{+}$H-2 ${ }^{\text {b }}$ CTLA-4 ${ }^{-1-}$ mice, respectively. Similar results were observed in the spleen although it appeared that the proportion of total $\mathrm{T}$ cells in the spleen was more strikingly reduced in Ly49Tg $^{+}$H-2 ${ }^{\mathrm{d}}$ CTLA-4 ${ }^{-1-}$ mice compared to the wild-type controls (data not shown). CD4 ${ }^{+} \mathrm{T}$ cells in $\mathrm{Ly} 49 \mathrm{Tg}^{+} \mathrm{CTLA}^{-4^{-1}}$ mice expressing $\mathrm{H}-2 \mathrm{D}^{\mathrm{d}}$ exhibit a diminished activation phenotype

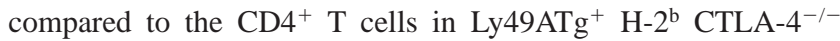
mice, and display a phenotype similar although not identical to the $\mathrm{T}$ cells in CTLA-4 wild-type mice (Figure 2). Most strikingly, the $\mathrm{H}-2^{\mathrm{d}}$ CTLA $-4^{-1-} \mathrm{T}$ cells expressing the Ly49A transgene showed a significantly reduced proportion of $\mathrm{CD} 69^{+}, \mathrm{CD} 44^{\text {high }}$, and CD45RB ${ }^{\text {low }}$ activated $\mathrm{T}$ cells compared to the H-2 $2^{\mathrm{b}}$ CTLA-4 deficient $\mathrm{T}$ cells that do not express the appropriate Ly49A ligand (Figure 2).

Down-modulation of the Ly49ATg receptor cell surface expression occurs in the presence of the $\mathrm{H}-2 \mathrm{D}^{\mathrm{d}}$ ligand, ${ }^{19}$ as has been shown to occur for the endogenous Ly 49 molecules. ${ }^{24}$ The CD44 ${ }^{\text {high }}$ $\mathrm{T}$ cells in the $\mathrm{Ly}_{49 \mathrm{ATg}}{ }^{+} \mathrm{H}-2 \mathrm{D}^{\mathrm{d}} \mathrm{CTLA}-4^{-1-}$ mice are predominantly Ly49Tglow, suggesting that after Ly49A receptor engagement and consequent decrease in cell surface expression of the receptor, some CTLA-4 $4^{-1-}$ T cells may become activated (data not shown). Hence, sustained and complete prevention of the lymphoproliferative disorder due to the absence of CTLA-4 appears to require persistent expression of the Ly49A inhibitory receptors.
A

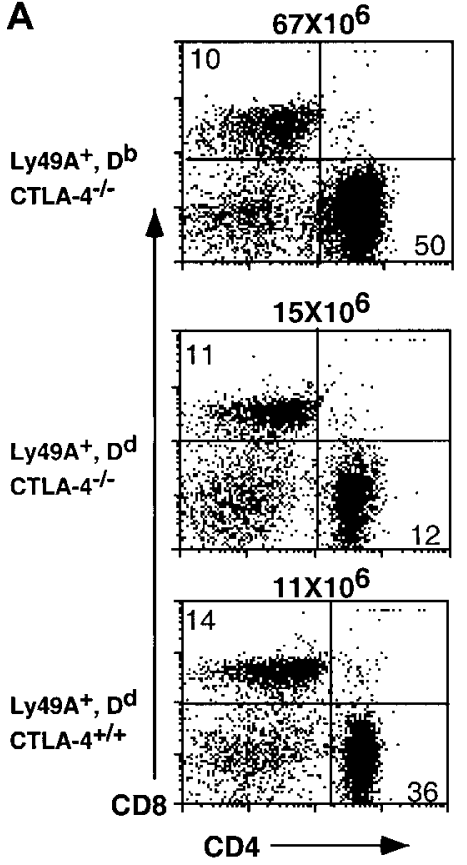

B
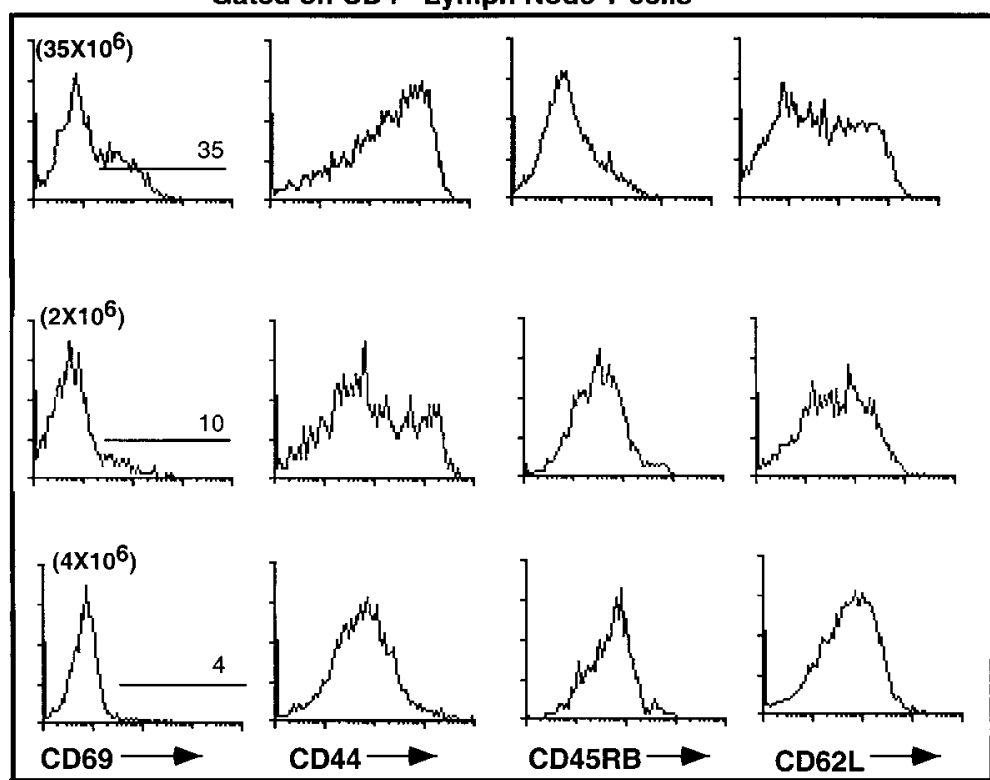

Figure 2. Ly49A-mediated inhibitory signals upon interaction with H-2Dd prevent the activation of CD4+ ${ }^{+}$cells. Representative flow cytometric analysis of CTLA-4 ${ }^{-/-}$ T cells from animals expressing the Ly49ATg in the presence and absence of the appropriate MHC class I compared to Ly49ATg ${ }^{-}$CTLA-4 ${ }^{-1-}$ mice and littermate controls ( 3 weeks of age). Lymph node cells were incubated with the antibodies indicated and analyzed by flow cytometry as described. ${ }^{22}$ (A) Total lymph node T cells were stained for CD4 and CD8. (B) The expression of the indicated activation/memory cell surface markers on the CD4+ lymph node $\mathrm{T}^{+}$cells from Ly49ATg ${ }^{+} \mathrm{D}^{\mathrm{b}} \mathrm{CTLA}-4^{-/-}$, Ly49ATg ${ }^{-} \mathrm{H}-2 \mathrm{D}^{\mathrm{d}}$ CTLA $-4^{-1-}$ and littermate control mice. The Ly49ATg ${ }^{+} D^{\mathrm{b}}$ CTLA-4 ${ }^{-1-}$ T cells have an activated phenotype similar to that observed in Ly49ATg ${ }^{-}$CTLA-4 ${ }^{-1-}$ mice (data not shown; see also Chambers et al ${ }^{5}$ ). These results are representative of more than 10 independent experiments. 


\section{Liver}
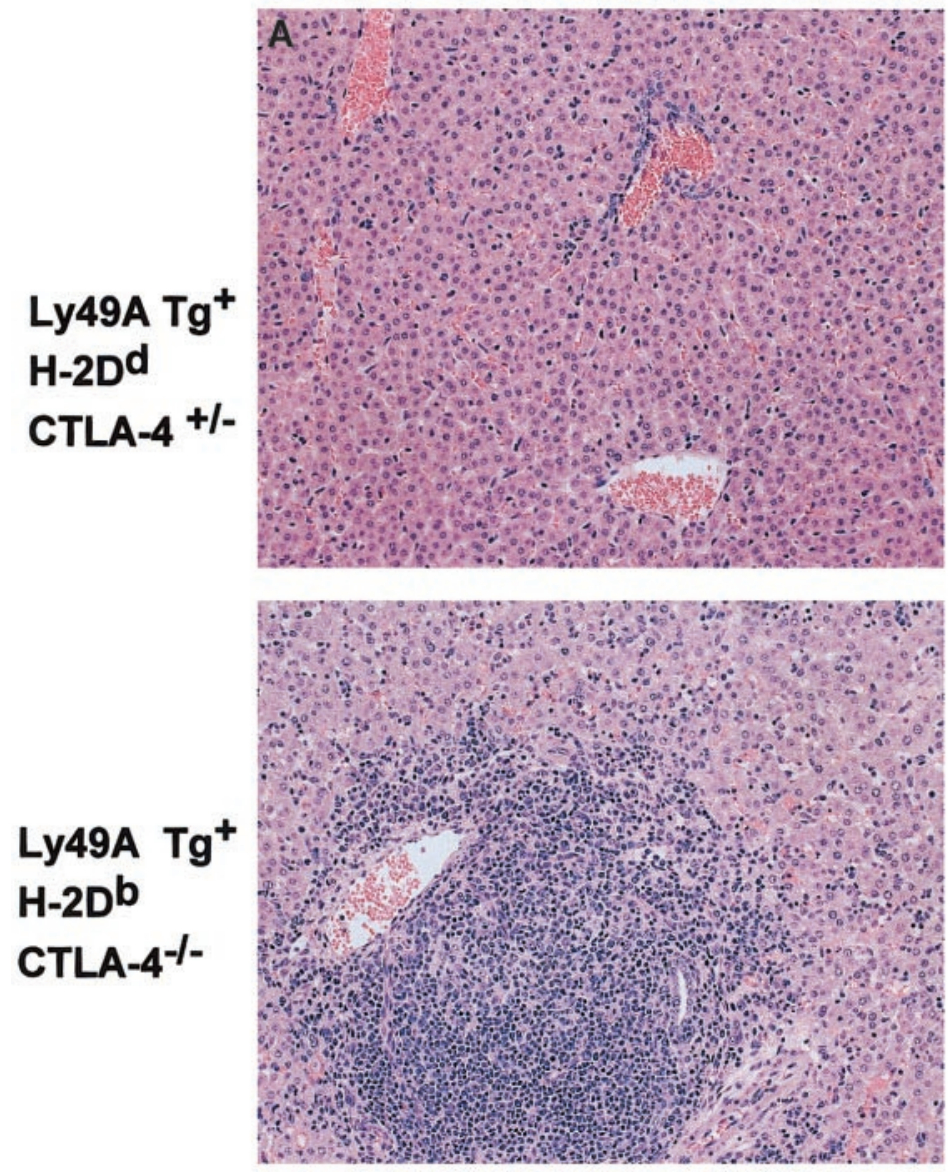

\section{Ly49A $\mathrm{Tg}^{+}$ \\ H-2Dd CTLA-4-}
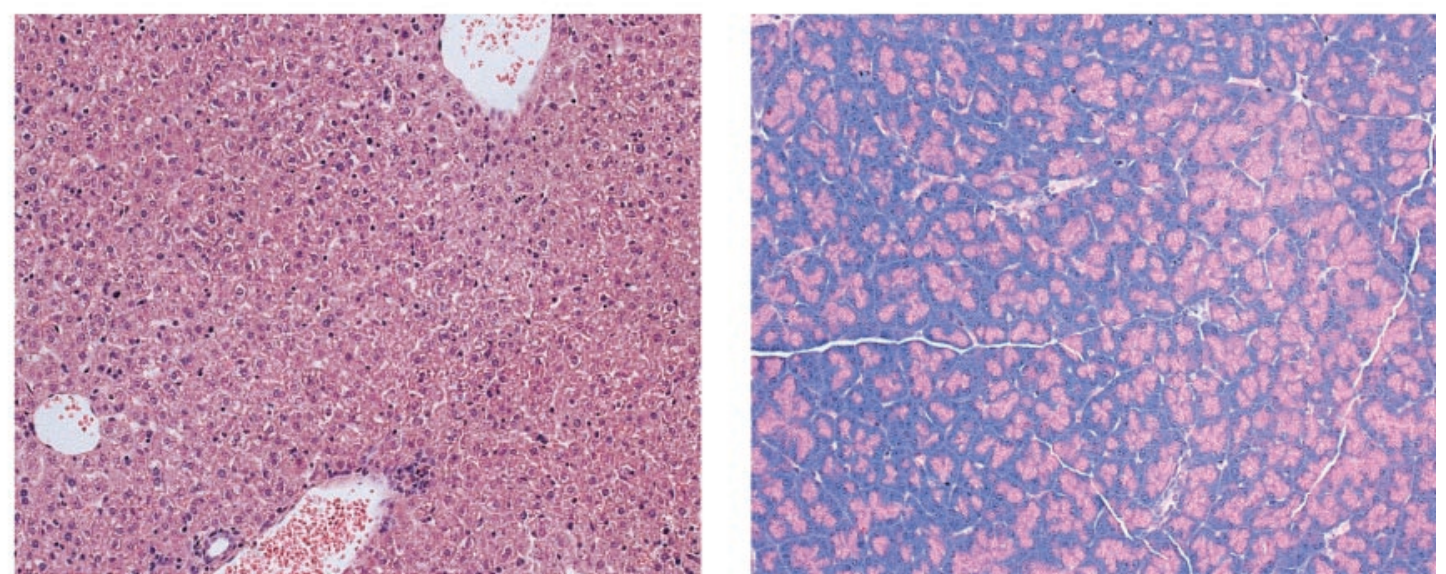

Figure 3. Ly49A transgene interaction with $H-2 D^{d}$ prevents the infiltration of lymphocytes into nonlymphoid tissues in CTLA-4-deficient mice. Dramatic infiltration of the nonlymphoid tissues was observed in the CTLA-4 $4^{-/-}$mice expressing the Ly49ATg in the absence of MHC class I-D ${ }^{d}$, whereas there was no apparent T-cell infiltration in the Ly49ATg ${ }^{+} \mathrm{H}-2 \mathrm{D}^{\mathrm{d}} \mathrm{CTLA}-4^{-l-}$ mice. Tissues were fixed in $10 \%$ buffered formalin and embedded in paraffin blocks. Sections were cut and stained with hematoxylin and eosin by conventional techniques. The representative data shown (of $>10$ independent experiments) are tissue sections from liver (A) and pancreas (B) of animals 3.5 weeks of age. No overt lymphocytic infiltration into nonlymphoid tissue was observed in the Ly $49 \mathrm{ATg}^{+} \mathrm{H}-2 \mathrm{D}^{\mathrm{d}} \mathrm{CTLA}-4^{-/-}$mice at 5 to 6 weeks of age (data not shown). Magnification, $\times 250$.

This result is consistent with the model that the CTLA-4 $4^{-1-}$ T cells are receiving continuous activating signals even in the absence of exogenous antigen stimulation in vivo.

Lymphocytic infiltration into nonlymphoid tissues in CTLA$4^{-1-}$ mice is inhibited by the ligation of Ly49A. CTLA- $4^{-1-}$ mice display extensive infiltration of lymphoid cells into nonlymphoid tissues such as the liver, heart, lung, and pancreas that results in a severe pancreatitis and fatal myocarditis in CTLA- $4^{-1-}$ animals. ${ }^{3-5}$ Similarly, extensive lymphocytic infiltration into the liver, pancreas (representative data shown in Figure 3), heart, and skin (data not shown) was observed in the $\mathrm{Ly}_{49 \mathrm{ATg}}{ }^{+} \mathrm{H}-2 \mathrm{D}^{\mathrm{b}} \mathrm{CTLA}-4^{-1-}$ mice compared to the littermate CTLA- ${ }^{+/+}$, CTLA- $4^{+/-}$controls (Figure 3). In contrast, histologic analysis of tissues from Ly49ATg ${ }^{+}$ H-2Dd CTLA- $4^{-1-}$ mice showed a greatly diminished infiltration of lymphocytes into nonlymphoid tissues compared to those of Ly49ATg ${ }^{+/-}$H-2D ${ }^{\text {b }}$ CTLA-4-deficient mice (Figure 3: liver, pancreas; lung, heart, data not shown). These results demonstrate that the expression of an NK cell inhibitory receptor on T cells prevents 
Figure 4. Ly49A-mediated inhibition decreases the total lymphoid cellularity by decreasing the T-cell turnover and survival. (A) Mice were pulsed for 2 days with $\mathrm{BrdU}$ and the remaining levels of BrdU incorporation after the indicated chase times were detected by flow cytometry as described in "Materials and methods." (B) Annexin V binding was assessed on the lymphocytes ex vivo, as an indicator of apoptosis. The cells were incubated with the indicated antibodies and annexin $V$ and analyzed by flow cytometry as described in "Materials and methods." These data are representative of 3 independent experiments. In all experiments mice were approximately 3 weeks of age at the time of analysis.
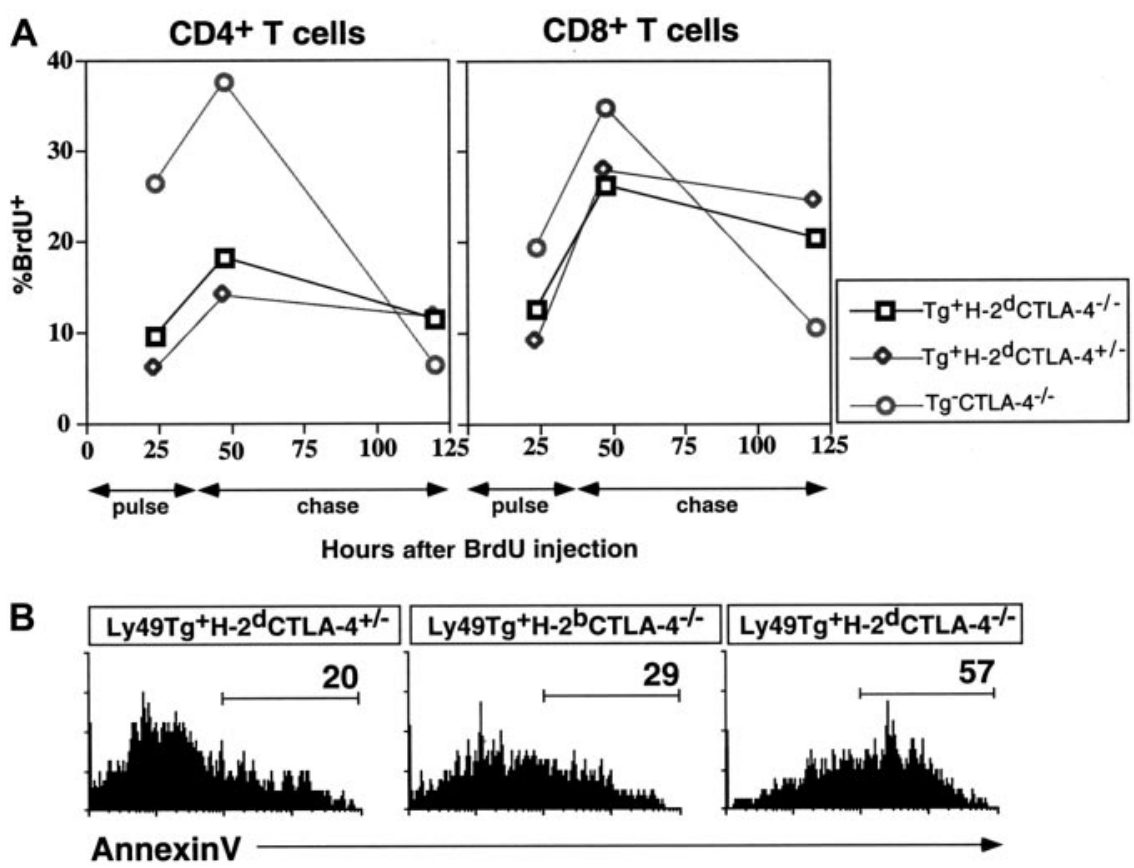

aberrant T-cell infiltration of tissues in the CTLA-4 $4^{-1-}$ mice, as well as inhibiting T-cell activation. Similarly there was no overt lymphoproliferation in the Ly49ATg ${ }^{+} \mathrm{H}-2 \mathrm{D}^{\mathrm{d}} \mathrm{CTLA}-4^{-1-}$ at 5 to 6 weeks of age (data not shown).

\section{Ly49A ligation inhibits T-cell activation and proliferation by inhibiting the number of cells in the cell cycle and by increased cell death}

The cellular and biochemical basis for the rescue of the CTLA-4 deficiency by Ly49ATg-mediated signals was examined. To determine if the compensatory signal prevented T-cell division, we measured the incorporation of thymidine analog BrdU following continuous labeling, as well as the rate of decay of incorporated BrdU in the $\mathrm{T}$ cells. There was a 2.7- to 4.5-fold increase in the percentage of $\mathrm{CD}^{+} \mathrm{T}$ cells positive for BrdU incorporation in the CTLA-4 $4^{-1-}$ mice compared to CTLA-4 wild-type mice (Figure 4), as previously described. ${ }^{5}$ The expression of the Ly49A transgene did not significantly alter the level of BrdU incorporation in T cells in the normal mice $\left(\mathrm{D}^{\mathrm{b}}\right.$ or $\mathrm{D}^{\mathrm{d}}$ background, data not shown). There was a 2- to 3-fold decrease in the percentage of $\mathrm{BrdU}^{+} \mathrm{CD}^{+}{ }^{+} \mathrm{T}$ cells in the lymph node (Figure 4A) and spleen (data not shown) in $\mathrm{Ly}_{49 \mathrm{ATg}^{+}}$ H-2D ${ }^{d}$ CTLA-4 ${ }^{-1-}$ mice compared to the Ly49ATg $^{+}$ H-2D ${ }^{\text {b CTLA }-4^{-1-} \text { or Ly49ATg }}{ }^{-}$CTLA- $4^{-1-}$ mice. Following a 3-day chase, the proportion of the $\mathrm{CD}^{+} \mathrm{T}$ cells staining for BrdU incorporation decreased dramatically in the CTLA-4 ${ }^{-1-}$ mice to one sixth the level detected after the 2-day pulse. For both control and rescued CTLA- $4^{-1-}$ mice the remaining BrdU incorporation in $\mathrm{CD}^{+}{ }^{+} \mathrm{T}$ cells was decreased less than 2 -fold compared to the levels at 2-day pulse. The difference for $\mathrm{CD}^{+}$ $\mathrm{T}$ cells was less striking, although the levels of BrdU labeling decreased 3-fold in CTLA-4 ${ }^{-1-}$ mice following the chase, whereas there was a minimal decrease in the proportion of BrdU-staining cells for control or rescued CTLA-4 ${ }^{-1-}$ mice. These results indicate that $\mathrm{T}$ cells from the rescued CTLA- $4^{-1-}$ $\left(\right.$ Ly49ATg $\left.{ }^{+} \mathrm{H}-2 \mathrm{D}^{\mathrm{d}}\right)$ mice, particularly $\mathrm{CD}^{+} \mathrm{T}$ cells, have a decelerated turnover rate compared to the CTLA-4-deficient T cells. Ly49A-mediated signaling in $\mathrm{T}$ cells maintains a nearnormal rate of turnover in the absence of CTLA-4-mediated signals. These results indicate that prevention of T-cell activation by Ly49A-mediated inhibitory signals is one mechanism important for preventing the lymphoproliferative disorder in CTLA-4 ${ }^{-1-}$ mice.

Another possible mechanism that could result in decreased cellularity in the H-2 $\mathrm{D}^{\mathrm{d}}$ CTLA-4 ${ }^{-1-}$ mice expressing the Ly49A transgene could be an increase in the proportion of cells undergoing cell death. To examine this possibility the proportion of the cells staining with annexin $\mathrm{V}$, a protein that binds to membrane phospholipid phosphatidylserine on the surface of apoptotic cells was examined. As shown in Figure 4B, there was an increase in the proportion of annexin $\mathrm{V}^{+} \mathrm{CD}^{+} \mathrm{T}$ cells in the spleen of $\mathrm{Ly}_{49 \mathrm{ATg}^{+}}$ $\mathrm{H}-2 \mathrm{D}^{\mathrm{d}}$ CTLA- $4^{-1-}$ mice compared to the nontransgenic CTLA$4^{-1-}$ mice and wild-type controls. The enhanced frequency of annexin $\mathrm{V}^{+}$cells was particularly noticeable for the splenic $\mathrm{CD}^{+}$ T cells $\left(\mathrm{Ly}_{49 \mathrm{ATg}}{ }^{+} \mathrm{H}-2 \mathrm{D}^{\mathrm{d}} \mathrm{CTLA}-4^{-1-}: 57.8 \% \pm 6.3 \%\right.$ [average \pm SEM], $\mathrm{n}=4$; Ly49ATg $^{+}$H-2D ${ }^{\mathrm{b}}$ CTLA-4 $4^{-1-}: 34.9 \% \pm 8.8 \%$, $\mathrm{n}=4 ; P<.05$, Student $t$ test). A difference in the percentage of annexin $\mathrm{V}^{+} \mathrm{CD}^{+} \mathrm{T}$ cells in the Ly49ATg ${ }^{+} \mathrm{H}-2 \mathrm{D}^{\mathrm{d}} \mathrm{T}$ cells was consistently observed, although it was not statistically significant Ly49ATg $^{+}$H-2D CTLA-4 $^{-1-}: 25.2 \% \pm 6.3 \%$ versus Ly49ATg ${ }^{+}$ H-2D ${ }^{\text {b }}$ CTLA-4 $\left.{ }^{-1-}: 16.8 \% \pm 8.8 \%\right)$. Collectively, these results suggest that the Ly49A transgene rescued the CTLA-4-deficient phenotype by a combination of prevention of T-cell activation leading to a decrease in T-cell turnover, and an increase in T-cell death. Both mechanisms result in an overall reduction in the absolute number and proportion of peripheral $\mathrm{T}$ cells.

\section{Ly49A ligation reverses the tyrosine hyperphosphorylation of some of the proteins in the early and late signaling pathways in CTLA-4 ${ }^{-1-} \mathrm{T}$ cells}

The absence of CTLA-4 results in tyrosine hyperphosphorylation of a number of proteins involved in the TCR signaling pathway. ${ }^{25}$ To determine if this pattern is modulated by the Ly49A-mediated inhibitory biochemical signals, the quantity 
and quality of total tyrosine phosphorylation in the purified lymph node T cells ex vivo from the rescued $\mathrm{Ly}_{49} \mathrm{ATg}^{+} \mathrm{H}-2 \mathrm{D}^{\mathrm{d}}$ CTLA-4 ${ }^{-1-}$ animals compared to CTLA-4 ${ }^{-1-}$ and wild-type control animals was examined. Hyperphosphorylation of a number of proteins was detected in lysates of purified lymph

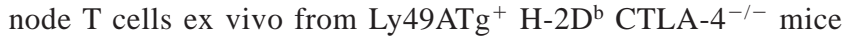
(Figure 5A), as has been reported for CTLA-4 $4^{-1-}$ mice. ${ }^{25}$ In the presence of $\mathrm{Ly}_{49 \mathrm{ATg}^{+}}$ligation by MHC class I $\mathrm{D}^{\mathrm{d}}$, the pattern of total tyrosine phosphorylation in the CTLA- $4^{-1-}$ mice was altered and was very similar to the littermate control (Figure 5A). Most strikingly, there was a decreased level of phosphorylation of bands corresponding to p110, p42, p36, and a number of proteins between p55 and $80 \mathrm{kd}$ (Figure 5A) and 20 to $25 \mathrm{kd}$ (data not shown). Tyrosine phosphorylation patterns of several other proteins implicated in $\mathrm{T}$ and NK cell signaling, including Vav and PLC $\gamma 1$, did not appear to be differentially phosphorylated between the rescued Ly49ATg ${ }^{+} \mathrm{H}-2 \mathrm{D}^{\mathrm{d}} \mathrm{CTLA}-4^{-1-}$ or the Ly49ATg ${ }^{+/-} \mathrm{H}-2 \mathrm{D}^{\mathrm{b}}$ CTLA-4 $4^{-1-}$ mice (data not shown).

One of the proteins that had decreased tyrosine phosphorylation in the $\mathrm{Ly}_{49 \mathrm{ATg}}{ }^{+} \mathrm{H}-2 \mathrm{D}^{\mathrm{d}} \mathrm{CTLA}-4^{-1-}$ T cells was mitogen-activated protein kinase ERK2 (Figure 5B), a downstream component of the ras signaling pathway (for a review, see Cantrell ${ }^{26}$ ). ERK2 phosphorylation is reported to be dependent on TCR signaling and independent of CD28-mediated signals. The decrease in ERK2 phosphorylation is consistent with the observed inhibition of the early activation marker CD69 expression strikingly apparent in the $\mathrm{CD}^{+} \mathrm{T}$ cells in the rescued Ly49ATg ${ }^{+} \mathrm{H}-2 \mathrm{D}^{\mathrm{d}} \mathrm{CTLA}^{-} 4^{-1-}$ mice (Figure 2) because CD69 expression is induced in a CD28independent, Ras-dependent manner. ${ }^{27}$

Phosphorylation of the $\mathrm{CD} 3 \zeta$ chain is one of the most proximal events in TCR-mediated T-cell activation (for a review, see van Leeuwen et $\mathrm{al}^{28}$ ). In freshly isolated thymocytes and peripheral $\mathrm{T}$

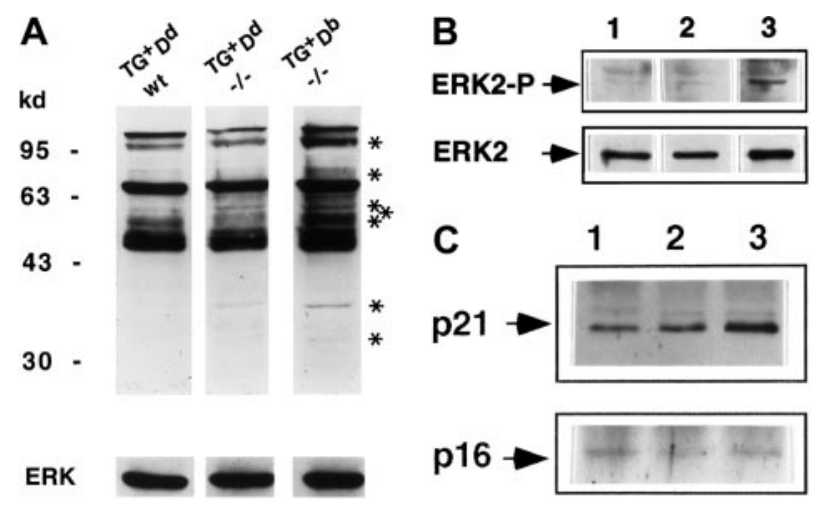

Figure 5. Ly49A-mediated inhibitory signals diverge and converge with the CTLA-4 signaling pathway. (A) Total tyrosine phosphorylation in lysates of purified lymph node T cells ex vivo. Lysates were equalized for total protein content and the proteins were separated by sodium dodecyl sulfate-polyacrylamide gel electrophoresis (SDS-PAGE; 8\%; lane 1: Ly49ATg ${ }^{+} \mathrm{D}^{\mathrm{d}}$ CTLA-4 $4^{+/,++-}$; lane 2: Ly49ATg ${ }^{+} \mathrm{D}^{\mathrm{d}}$ CTLA-4 ${ }^{-1-}$; lane 3: Ly49ATg ${ }^{+} \mathrm{D}^{\mathrm{b}}$ CTLA-4 $4^{-1-}$ ). The phosphoproteins were detected by Western blotting using antiphosphotyrosine antibody $4 \mathrm{G} 10$. These data are representative of 7 independent experiments. Asterisks indicate bands uniquely phosphorylated in the CTLA $-4^{-1-} \mathrm{T}$ cells from mice that develop lymphoproliferation but not in the "rescued" (Ly49ATg ${ }^{+/-} \mathrm{D}^{\mathrm{d}}$ ) CTLA-4 $4^{-1-}$ or in the littermate control animals. (B) Phosphorylated ERK2 was detected by Western blot total protein with anti-EK2 tyrosine phosphorylation-specific antibody. The blots in panels $A$ and $B$ were stripped and reprobed with anti-ERK2 antibody (lanes are as indicated in panel A). This is representative of 3 independent experiments. (C) CD3 $\zeta$ phosphorylation. Lysates of equivalent total protein were immunoprecipitated by anti-CD3 $\zeta$ antibody 387 . Immunoprecipitates (lanes are as indicated in panel A) were separated by SDS-PAGE $(12 \%)$ and phosphoproteins were detected by Western blotting using antiphosphotyrosine antibody $4 \mathrm{G} 10$. The blots were stripped and reprobed with anti-CD3 $\zeta$ antibody. This is representative of 3 independent experiments. cells, the CD3 $\zeta$ ITAM motifs are partially phosphorylated (p21). ${ }^{29,30}$ On optimal T stimulation, CD3 $\zeta$ ITAM tyrosine phosphorylation is saturated and the completely phosphorylated CD3 $\zeta$ (molecular weight of $23 \mathrm{Kd}$ [p23]) becomes the predominant form. ${ }^{29,30}$ Interestingly, there is an increase in the p21 species in the CTLA-4 ${ }^{-1-} \mathrm{T}$ cells ex vivo. Further, the p21 form remained the dominant phosphorylated form of $\mathrm{CD} 3 \zeta$ (Figure 5C), with the fully phosphorylated p 23 form of $\mathrm{CD} 3 \zeta$ below detection in the CTLA- $4^{-1-}$ T cells despite the fact that these $\mathrm{T}$ cells are activated and are dividing in

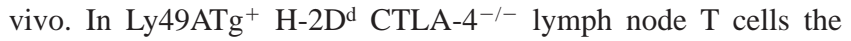
overall pattern of $\mathrm{CD} 3 \zeta$ phosphorylation is similar to littermate controls, but importantly, the level of tyrosine phosphorylation of the p21 form of $\mathrm{CD} 3 \zeta$ significantly decreased compared to the CTLA $-4^{-1-}$ T cells (Figure 5C). These results indicate that Ly49A ligation reduces the level of tyrosine phosphorylation of $\mathrm{CD} 3 \zeta$ in $\mathrm{T}$ cells in vivo and suggests that modulation of lymphoproliferation of CTLA- $4^{-1-} \mathrm{T}$ cells by Ly49A molecule is mediated in part by inhibiting proximal TCR signaling as well as the more distal Ras signaling pathway.

\section{Discussion}

Functional complementation of the ctla-4 mutation by an alternate dominant inhibitory receptor provides compelling evidence for the model that inhibitory signals play a crucial role in the maintenance of homeostasis of T cells. Previously we proposed a model for the role of CTLA-4 in regulating T-cell activation and the integration of the TCR, CD28, and CTLA-4 signals. ${ }^{31}$ It has been shown that continuous, low-level TCR signaling provides signals involved in peripheral T-cell survival/homeostasis. ${ }^{32-35}$ An extreme interpretation of the proposed model is that CTLA-4-mediated inhibitory signals function to prevent TCR interactions with self-MHC of sufficient affinity to generate stimulatory signals, in the presence of low levels of CD28/B7 interaction, from leading to full T-cell activation and thereby maintaining the $\mathrm{T}$ cells in a resting state. ${ }^{5}$ The results presented here demonstrate that an alternative dominant inhibitory signal can prevent CTLA-4 ${ }^{-/-}$T-cell activation, providing support for this model of CTLA-4 function.

The function of Ly49A in this model system is absolutely dependent on the presence of its cognate ligand $\mathrm{H}-2 \mathrm{D}^{\mathrm{d}}$. Overall, both $\mathrm{CD}^{+}$and $\mathrm{CD}^{+} \mathrm{T}$ cells showed decreased cell turnover in Ly49ATg ${ }^{+}$CTLA- $-4^{-1-}$ mice compared to CTLA-4 ${ }^{-1-}$ mice. However, $\mathrm{CD}^{+} \mathrm{T}$ cells appeared to be more susceptible to apoptosis in these mice compared to $\mathrm{CD} 4^{+} \mathrm{T}$ cells (Figure 4$)$. In a study examining the inhibitory NKR (KIR) function in $\mathrm{CD}^{+} \mathrm{T}$ cells, it has recently been reported that the KIR expression promotes accumulation of memory $\mathrm{CD} 8^{+} \mathrm{T}$ cells by moderating activationinduced cell death (AICD). ${ }^{36}$ This difference in the outcome for $\mathrm{CD}^{+}$T-cell survival on inhibitory NKR expression-enhanced apoptosis versus resistance to AICD-may be explained by distinct genetic components used in these 2 model systems. More interestingly, however, the difference may arise as a result of different activational status of $\mathrm{CD}^{+} \mathrm{T}$ cells in each system. In the KIR transgenic model system detection of increased numbers of memory $\mathrm{CD}^{+} \mathrm{T}$ cells required strong antigenic stimulation, whereas the CTLA- $4^{-1-}$ T cells in our model are stimulated to proliferate in the absence of foreign antigenic challenge. Hence, the activating stimuli, and the activational history of the T cells, may dictate the ultimate outcome of inhibitory NKR signaling. It has been 
proposed that expression of inhibitory NKR on activated virusspecific murine $\mathrm{CD}^{+} \mathrm{T}$ cells preferentially dampens the activation and expansion of low affinity $\mathrm{CD} 8^{+} \mathrm{T}$ cells, thereby resulting in the expansion of high-affinity $\mathrm{CD}^{+} \mathrm{T}$ cells that are less sensitive to inhibitory NKR signaling. ${ }^{20,37}$ The low-affinity effector $\mathrm{CD}^{+} \mathrm{T}$ cells expressing inhibitory NKR may then be subject to apoptosis. Increased apoptosis in Ly49A ${ }^{+} \mathrm{CTLA}_{-4^{-/-}}$ $\mathrm{CD}^{+} \mathrm{T}$ cells may be mimicking the fate of low-affinity $\mathrm{CD} 8^{+}$ effector $\mathrm{T}$ cells and is consistent with the idea that inhibitory NKR signaling can act as an apoptosis promoter of CD8 ${ }^{+} \mathrm{T}$ cells under some stimulation conditions. ${ }^{37}$ Further genetic and biochemical characterization will be required to determine how the physiology of the $\mathrm{CD}^{+} \mathrm{T}$ cells influences the fate of the $\mathrm{T}$ cell upon NKR ligation in vivo.

Although the Ly49A transgene interaction with $\mathrm{H}-2 \mathrm{D}^{\mathrm{d}}$ clearly prevents the lymphoproliferative disorder and lymphocytic infiltration into nonlymphoid tissues in the CTLA $-4^{-1-}$ mice, these mice do eventually become ill. The Ly49 $\mathrm{ATg}^{+} / \mathrm{D}^{\mathrm{d}} \mathrm{CTLA}-4^{-1-}$ animals die at approximately 5 to 6 weeks of age of a wasting disease. This disease is not due to expression of the Ly49A transgene, because the transgenic mouse line used in this study has been shown to remain healthy. ${ }^{19}$ One explanation for the wasting disease observed in the "rescued" CTLA- $4^{-1-}$ mice is the existence of an additional pathologic component of the CTLA-4 deficiency that is masked by the lymphoproliferation in CTLA- $4^{-1-}$ mice, and for which the Ly49A-mediated inhibitory signals cannot compensate. Interestingly, reconstitution of normal histocompatible mice with CTLA$4^{-1-}$ bone marrow $(100 \%)$ does not recapitulate the lymphoproliferation observed in mice deficient for CTLA-4. ${ }^{38}$ Instead, these mice develop a fatal wasting disease that phenotypically resembles graft-versus-host disease. ${ }^{38}$ Although it remains controversial, ${ }^{40}$ it has been postulated that suppression mediated by transforming growth factor $\beta$ (TGF- $\beta$ ) is deficient in the CTLA- $4^{-1-}$ bone marrow chimeric animals and in several other models of autoimmunity, due to the absence of CTLA- $4^{+}$immunoregulatory T cells..$^{38-41}$ Using the model system described here, it will be possible to determine if there are distinct mechanisms regulating the lymphoproliferative and the wasting disorders. Alternatively, the inflammation and eventual illness in the absence of lymphoproliferation may be as a result of altered cytokine production due to the Ly49Amediated inhibition. These possibilities are not mutually exclusive and delineation of them will provide insights into the pathologic components of the CTLA-4 deficiency as well as in understanding the function of NKR in regulating T-cell homeostasis.

Ultimately, understanding how $\mathrm{T}$ cells are normally regulated by inhibitory signals requires biochemical identification of physiologically relevant intracellular signal transducers and substrates. There is clear evidence for the role of tyrosine phosphatase activity in Ly49A-mediated inhibitory signals. Although SHP-2 and SHIP can bind to the Ly49A ITIM motifs, SHP-1 appears to be the primary phosphatase required for signal transduction (for a review, see Lanier ${ }^{43}$ ). Inhibitory NKR engagement prevents early protein tyrosine kinase (PTK)-dependent activation signals in NK cell lines. The picture for CTLA-4 signaling is less clear. There is considerable controversy concerning the mechanism(s) of CTLA-4 inhibition of T-cell activation. Tyrosine hyperphosphorylation of a number of proteins involved in TCR signaling was observed in CTLA-4-deficient $\mathrm{T}$ cells. ${ }^{25}$ This observation led to the proposal that CTLA-4 functions by recruiting tyrosine phosphatases. We have shown that normal levels of SHP-1 are not required for CTLA-4-mediated T-cell inhibition. ${ }^{43}$ Some evidence for a role for tyrosine phosphatase SHP-2 has been reported. Demonstration that catalytically active SHP-2 binds to the cytoplasmic tail of CTLA$4^{25,44}$ suggests that this tyrosine phosphatase is relevant. However, SHP-2 bound to phosphorylated polypeptides of CTLA-4 and CD28 cytoplasmic tails, ${ }^{45}$ making the interpretation of the role of SHP-2 in inhibitory T-cell signaling difficult. Recently serine/ threonine phosphatases PP2A and PP6 have been reported to bind to both CTLA-4 and CD28 cytoplasmic tails, ${ }^{46}$ although the functional significance of these interactions has not been determined. Alternative mechanisms, ${ }^{47-51}$ including competition with CD28 for ligand ${ }^{47-49}$ or the induction of TGF- $\beta$ secretion, ${ }^{51}$ have been suggested to function in some, but not all, circumstances. ${ }^{49,52}$ Further, because the activation status of the T cells, as well as the balance of the TCR- versus CD28-mediated signals, influence the function of CTLA-4, ${ }^{1}$ the mechanism of activation may vary under different conditions. These complexities have impeded progress in identifying specific intracellular signal transducers of CTLA-4, but nevertheless, the importance of tyrosine phosphatases has been well established and is a common theme for both Ly49- and CTLA-4-mediated signaling pathways.

The results presented here suggest that the Ly49A-mediated signaling pathway modifies the proximal and distal signaling pathways in $\mathrm{T}$ cells activated in vivo. The molecules $\mathrm{CD} 3 \zeta$ and ERK2 were found to be differentially phosphorylated in the Ly49ATg ${ }^{+}$H-2D CTLA-4 $^{-1-}$ compared to the CTLA-4 ${ }^{-1-}$ T cells. Importantly, it has been reported that CTLA-4 cross-linking on T-cell blasts decreased the levels of phosphorylation of CD3 $\zeta$ and ERK2. ${ }^{48,53}$ Although the data are suggestive of some convergence between Ly49 and CTLA-4 negative signaling in T cells at the level of both substrates and functional outcome, the exact biochemical components of each pathway still remain to be elucidated. Characterization of physiologically relevant protein interactions and phosphorylation status on dominant inhibitory signaling, leading to identification of points of convergence and divergence of the CTLA-4- and Ly49A-mediated signals can be performed using this model system.

CTLA- $4^{-1-}$ T cells are arguably one of the most autoaggressive cells found to date. The fact that other inhibitory receptors, such as PD- $1,{ }^{54}$ which is expressed on CTLA- $4^{-1-} \mathrm{T}$ cells (C.A.C., unpublished result, February 2001), cannot compensate for the absence of CTLA-4 clearly points to a physiologic relevance and convergent signaling pathways used by inhibitory Ly 49 molecules and CTLA-4 in T cells. Expression of the NKR on T cells has been observed in a number of scenarios, including recipients of allogeneic bone marrow transplants, aged individuals, and patients undergoing chronic viral infections, such as in those infected with human immunodeficiency virus, and in patients with melanoma. The results presented in this paper demonstrate that inhibitory NKR can regulate T-cell activation or proliferation in vivo. This occurred in the absence of immunization or antigenic challenge, suggesting that autoreactive peripheral $\mathrm{T}$ cells can be regulated by inhibitory NKR. Hence, these results have tangible clinical implications and this model system provides a novel approach toward understanding inhibitory NKR and CTLA-4 biology.

\section{Acknowledgments}

We thank Larry Samelson for the anti-CD3 $\zeta$ antibody 387, Dr M. Kuhns for helpful discussions, and Dr L. Berg for critical reading of the manuscript. 


\section{References}

1. Chambers CA, Kuhns MS, Egen JG, Allison JP. CTLA-4-mediated inhibition in regulation of $T$ cell responses: mechanisms and manipulation in tumor immunotherapy. Ann Rev Immunol. 2001;19: 565-594.

2. Chambers CA, Allison JP. Costimulatory regulation of T cell responses. Curr Opin Cell Biol. 1999;11:203-210.

3. Waterhouse P, Penninger JM, Timms E, et al. CTLA-4 deficiency causes lymphoproliferative disorder with early lethality. Science. 1995;270: 985-988.

4. Tivol EA, Borriello F, Schweitzer AN, Lynch WP, Bluestone JA, Sharpe AH. Loss of CTLA-4 leads to massive lymphoproliferation and fatal multiorgan tissue destruction, revealing a critical negative regulatory role for CTLA-4. Immunity. 1995;3: 541-546.

5. Chambers CA, Sullivan TJ, Allison JP. Lymphoproliferation in CTLA-4-deficient mice is mediated by costimulation-dependent activation of $\mathrm{CD}^{+}{ }^{+} \mathrm{T}$ cells. Immunity. 1997;7:885-895.

6. Tivol E, Boyd SD, McKeon S, et al. CTLA-4lg prevents lymphoproliferation and fatal multiorgan tissue destruction in CTLA-4-deficient mice. $\mathrm{J} \mathrm{Im}$ munol. 1997;158:5091-5094.

7. Hanke T, Takizawa H, McMahon CW, et al. Direct assessment of MHC class I binding by seven Ly49 inhibitory NK cell receptors. Immunity. 1999; 11:67-77.

8. Michaelsson J, Achour A, Salcedo M, et al. Visualization of inhibitory Ly 49 receptor specificity with soluble major histocompatibility complex class I tetramers. Eur J Immunol. 2000;30:300307.

9. Roland J, Cazenave PA. Ly-49 antigen defines an alpha beta TCR population in i-IEL with an extrathymic maturation. Int Immunol. 1992;4:699-706.

10. Bendalac A. Mouse NK1+ T cells. Curr Opin Immunol. 1995;7:367-374.

11. Lanier LL, Phillips JH. Inhibitory MHC class I receptors on NK cells and T cells. Immunol Today. 1996;17:86-91.

12. Mingari MC, Moretta A, Moretta L. Regulation of KIR expression in human T cells: a safety mechanism that may impair protective T-cell responses. Immunol Today. 1998;19:153-156.

13. Coles MC, McMahon CW, Takizawa H, Raulet $\mathrm{DH}$. Memory $\mathrm{CD}^{+}{ }^{+} \mathrm{T}$ lymphocytes express inhibitory MHC-specific Ly49 receptors. Eur J Immunol. 2000;30:236-244.

14. Ferrini S, Cambiaggi A, Meazza R, et al. T cell clones expressing the natural killer cell-related p58 receptor molecule display heterogeneity in phenotypic properties and p58 function. Eur J Immunol. 1994;24:2294-2298.

15. Mingari M, Vitale C, Cambiaggi A, et al. Cytolytic T lymphocytes displaying natural killer (NK)-like activity: expression of NK related functional receptors for HLA class I molecules (p58 and CD94) and inhibitory effect on the TCR-mediated target cell lysis or lymphokine production. Int Immunol. 1995;7:697-703.

16. Phillips JH, Gumperz JE, Parham P, Lanier LL Superantigen-dependent, cell-mediated cytotoxicity inhibited by MHC class I receptors on T lymphocytes. Science. 1995;268:403-405.

17. Mandelboim O, Davis DM, Reyburn HT, et al. Enhancement of class II-restricted T cell responses by costimulatory NK receptors for class I MHC proteins. Science. 1996;274:2097-2100.

18. Ikeda H, Lethe B, Lehamnn F, et al. Characterization of an antigen that is required on a melanoma showing partial HLA loss by CTL expressing an NK inhibitory receptor. Immunity. 1997;6:199-208.
19. Held W, Cado D, Raulet DH. Transgenic expression of the Ly49A natural killer cell receptor confers class I major histocompatibility complex (MHC)-specific inhibition and prevents bone marrow allograft rejection. J Exp Med. 1996;184: 2037-2041.

20. Zajac AJ, Vance RE, Held W, et al. Impaired antiviral T cell responses due to expression of the Ly49A inhibitory receptor. J Immunol. 1999;163: 5526-5534.

21. Brawand $P$, Lemonnier FA, MacDonald HR, Cerottini J-C, Held W. Transgenic expression of Ly49A on T cells impairs a specific tumor re sponse. J Immunol. 2000;165:1871-1876.

22. Chambers CA, Cado D, Truong T, Allison JP. Thymocyte differentiation is normal in the CTLA-4deficient mice. Proc Natl Acad Sci U S A. 1997; 94:9296-9301.

23. Wu YJ, Nadler MJS, Brennan LA, et al. SHP-1/ $C D 72$ interaction in the regulation of $B$ cell receptor-induced cell death. Curr Biol. 1998;8:1009 1017.

24. Höglund P, Sundback J, Olsson-Alheim MY, et al. Host MHC class I gene control of NK-cell specificity in the mouse. Immunol Rev. 1997;155:11-28.

25. Marengére LEM, Waterhouse $P$, Duncan GS, Mittrucker H-W, Feng G-S, Mak TW. Regulation of $T$ cell receptor signaling by tyrosine phosphatase SYP association with CTLA-4. Science. 1996;272:1170-1173.

26. Cantrell D. T cell antigen receptor signal transduction pathways. Annu Rev Immunol. 1996;14 259-274.

27. D'Ambrosio D, Cantrell DA, Frati L, Santoni A, Testi R. Involvement of p21 ras activation in T cell CD69 expression. Eur J Immunol. 1994;24:616620.

28. van Leeuwen JEM, Samelson LE. T cell antigenreceptor signal transduction. Curr Opin Immunol. 1999;11:242-248.

29. Neumeister-Kersh E, Shaw AS, Allen PM. Fidelity of T cell activation through multistep T cell receptor phosphorylation. Science. 1998;281:572-575.

30. van Oers NSC, Killeen N, Weiss A. ZAP-70 is constitutively associated with tyrosine-phosphorylated TCR $\zeta$ in murine thymocytes and lymph node T cells. Immunity. 1994;1:675-685.

31. Chambers CA, Krummel MF, Boitel B, et al. The role of CTLA-4 in the regulation and initiation of T cell responses. Immunol Rev. 1996;153:27-46.

32. Tanchot $C$, Lemonnier FA, Pérarnau B, Freitas $A A$, Rocha B. Differential requirements for survival and proliferation of CD8 naive or memory cells. Science. 1997;276:2057-2062.

33. Brocker T. Survival of mature CD4 T lymphocytes is dependent on major histocompatibility complex class II-expressing dendritic cells. J Exp Med. 1997;186:1223-1232.

34. Kirberg J, Berns A, von Boehmer H. Peripheral cell survival requires continual ligation of the $T$ cell receptor to major histocompatibility complexencoded molecules. J Exp Med. 1997;186:12691275.

35. Takeda S, Rodewald H-R, Arakawa H, Bluethmann H, Shimizu T. MHC class II molecules are not required for survival of newly generated CD4 ${ }^{+}$ $T$ cells but affect their long-term life span. Immunity. 1996;5:217-228.

36. Ugolini S, Arpin C, Anfossi N, et al. Involvement of inhibitory NKRs in the survival of a subset of memory-phenotype CD8+ T cells. Nat Immunol. 2001:2:430-435.

37. McMahon CW, Raulet DH. Expression and func- tion of NK cell receptors in CD8 + T cells. Curr Opin Immunol. 2001;13:465-470.

38. Bachmann MF, Köhler G, Ecabert B, Mak TW, Kopf M. Lymphoproliferation disease in the absence of CTLA-4 is not T cell autonomous. J Immunol. 1999;163:1128-1131.

39. Salomon B, Lenschow DJ, Rhee L, et al. B7/ CD28 costimulation is essential for the homeostasis of the $\mathrm{CD} 4{ }^{+} \mathrm{CD} 25^{+}$immunoregulatory $\mathrm{T}$ cells that control autoimmune diabetes. Immunity. 2000;12:431-440.

40. Read S, Malmström V, Powrie F. Cytotoxic T lymphocyte-associated antigen 4 plays an essential role in the function of $\mathrm{CD} 25^{+} \mathrm{CD} 4^{+}$regulatory cells that control intestinal inflammation. J Exp Med. 2000;192:295-302.

41. Takahashi T, Tagami T, Yamazaki S, et al. Immunologic self-tolerance maintained by $\mathrm{CD} 25^{+} \mathrm{CD} 4$ regulatory $\mathrm{T}$ cells constitutively expressing cytotoxic T lymphocyte-associated antigen 4. J Exp Med. 2000;192:303-310.

42. Lanier LL. Natural killer cell receptors and MHC class I interactions. Curr Opin Immunol. 1997:9: 126-131.

43. Chambers CA, Allison JP. The role of tyrosine phosphorylation and PTP-1C in CTLA-4 signaling. Eur J Immunol. 1996;26:3224-3229.

44. Lee K-M, Chuang E, Griffin M, et al. Molecular basis of T cell inactivation by CTLA-4. Science. 1998;282:2263-2266.

45. Zhang Y, Allison JP. Interaction of CTLA-4 with AP-50, a clathrin-coated pit adaptor protein. Proc Natl Acad Sci U S A. 1997;94:9273-9278.

46. Chuang E, Fisher TS, Morgan RW, et al. The CD28 and CTLA-4 receptors associated with the serine/threonine phosphatase PP2A. Immunity. 2000;13:313-322.

47. Nakaseko C, Miyatake S, lida T, et al. Cytotoxic T lymphocyte antigen 4 (CTLA-4) engagement delivers an inhibitory signal through the membraneproximal region in the absence of the tyrosine motif in the cytoplasmic tail. J Exp Med. 1999; 190:765-774.

48. Baroja ML, Luxenberg $\mathrm{D}$, Chau T, et al. The inhibitory function of CTLA-4 does not require its tyrosine phosphorylation. J Immunol. 2000;164 $49-55$.

49. Masteller EL, Chuang E, Mullen AC, Reiner SL, Thompson CB. Structural analysis of CTLA-4 function in vivo. J Immunol. 2000;164:5319-5327.

50. Cinek T, Sadra A, Imboden JB. Tyrosine-independent transmission of inhibitory signals by CTLA-4. $\mathrm{J}$ Immunol. 2000;164:5-8.

51. Chen W, Jin W, Wahl SM. Engagement of cytotoxic T lymphocyte-associated antigen 4 (CTLA-4) induces transforming growth factor $\beta$ (TGF- $\beta$ ) production by murine CD4 ${ }^{+} \mathrm{T}$ cells. J Exp Med. 1998;188:1849-1857.

52. Sullivan TJ, Letterio JJ, van Elsas A, et al. Lack of a role for transforming growth factor- $\beta$ in cytotoxic $T$ lymphocyte antigen-4-mediated inhibition of $T$ cell activation. Proc Natl Acad Sci USA. 2001;98: 2587-2592.

53. Calvo CR, Amsen D, Kruisbeek AM. Cytotoxic $T$ lymphocyte antigen 4 (CTLA-4) interferes with extracellular signal-regulated kinase (ERK) and Jun $\mathrm{NH}_{2}$-terminal kinase (JNK) activation, but does not affect phosphorylation of T cell receptor $\zeta$ and ZAP70. J Exp Med. 1997;186:1645-1653.

54. Freeman GJ, Long AJ, Iwai Y, et al. Engagement of the PD-1 immunoinhibitory receptor by a novel B7 family member leads to negative regulation of lymphocyte activation. J Exp Med. 2000;192: 1027-1034. 